\title{
Solid State Characterization and Tableting Studies of Ethanol Based Cocrystals of Fenofibrate with Nicotinamide
}

\author{
Amol Somanath Shete ${ }^{1 *}$, Vishwajeet V Khandagale ${ }^{2}$, Srinivasa M Murthy ${ }^{3}$, Adhikrao Vyankatrao \\ Yadav $^{4}$, Sfurti Shamling Sakhare ${ }^{4}$, Rajendra Chandrashekhar Doijad ${ }^{1}$
}

${ }^{1}$ Department of Pharmaceutics, Krishna Institute of Pharmacy of Krishna Institute of Medical Sciences Deemed University, Karad, INDIA.

2Department of pharmaceutics and Quality Assurance, Shree Santkrupa College of Pharmacy, Ghogaon, Karad, INDIA.

${ }^{3}$ Vignan Institute of Pharmaceutical Sciences, Deshmukhi, Nalgonda, INDIA.

${ }^{4}$ Gourishankar Institute of Pharmaceutical Education and Research, Limb, Satara, INDIA.

\begin{abstract}
Objectives: The pharmaceutical cocrystals can be defined as dissociable "API-excipient" molecular complexes or Co-crystals are solids that are crystalline materials composed of two or more molecules in the same crystal lattice as per U.S. Department of Health and Human Services Food and Drug Administration Center for Drug Evaluation and Research (CDER) April 2013. The objectives of present investigation were to formulate cocrystals of fenofibrate with nicotinamide by solution cocrystallization technique. Methods: The cocrystals were prepared by solution cocrystallization technique by using ethanol as a solvent and nicotinamide as a coformer in the ratio of $1: 1 \& 1: 2$. The prepared cocrystals were evaluate for, solid state characterization by FTIR, PXRD, Raman spectroscopy and evaluated for tableting performance. Results: The formation of cocrystals has been confirmed by FTIR and Raman spectroscopy. The formulations $1: 1$ and 1:2 ratios showed better flow properties. The order of tableting performance $1: 2$ ratio cocrystals $>1: 1$ ratio cocrystals $>$ Recrystallized nicotinamide $>$ Nicotinamide $>>$ Recrystallized Fenofibrate $>>$ Fenofibrate. Conclusion: The cocrystals showed superior tableting performance. This might be due to the co-crystals, contains hydrogen-bonded two dimensional flat slip planes which exhibits higher plasticity.
\end{abstract}

Key words: Cocrystals, Crystallizaton, Fenofibrate, Nicotinamide, Tableting

\section{INTRODUCTION}

Cocrystals can be defined as crystalline materials consist of two or more different components (or commonly called multicomponent crystals). For the pharmaceutical cocrystals, one component is an active pharmaceutical ingredient and other components are called as coformers. Cocrystals have gained considerable interest in pharmaceutical research due to its ability to improve physicochemical characteristics of an API such as such as mechanical behavior, compressibility, solubility, dissolution rate, moisture stability, and bioavailability of drugs with their chemical structure unchanged. ${ }^{1,2}$ In a short time span cocrystals are of the interest of the researchers because fast forward to 2015 and the first example of a pharmaceutical ionic cocrystal drug was approved by the US-FDA in accordance with its cocrystal guidance paper for drug substances in 2012 $-2013 .{ }^{3}$ Entresto is a novel drug launched by Novartis for the treatment of chronic heart failure with the composition monosodium sacubitril, disodium valsartan, and water. Other examples include escitalopram oxalate. ${ }^{4}$ a marketed drug in a crystal form that is composed of protonated escitalopram cations, water molecules, oxalate dianions, and diprotonated oxalic acid molecules. The anti-diabetes drug Ertugliflozin. ${ }^{5}$ currently
Submission Date: 13-07-2017; Revision Date: 25-09-2017; Accepted Date: 10-01-2018

DOI: 10.5530/ijper.52.1.8 Correspondence: Mr.Amol Somanath Shete, Department of Pharmaceutics, Krishna Institute of Pharmacy of Krishna Institute of Medical Sciences Deemed University, Karad, - 415110 INDIA.

Phone no: 09822916129 E-mail: amol.shete@rediffmail.com

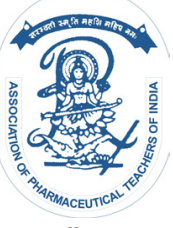

www.ijper.org 
in phase III clinical development is a cocrystal with 5-oxo-proline.

Fenofibrate is a neutral, lipophilic compound that is practically insoluble in water, making it challenging to consistently achieve therapeutic levels. ${ }^{6}$ Our previous investigation showed nicotinamide forms stable cocrystals theoretically and practically with fenofibrate with improved dissolution rate. ${ }^{7}$

In general, fenofibrate products can be grouped with regard to their food effects. For example, fenofibrate formulations that should be taken with meals include non-micronized tablets (Fenoglide ${ }^{\circledR}$, Lofibra ${ }^{\circledR}$, generic), micronized capsules (Lofibra ${ }^{\circledR}$ and generic), micro coated micronized tablets (Lofibra ${ }^{\circledR}$ ), and fenofibrate hard gelatin capsules (Lipofen $\left.{ }^{\circledR}\right)$. Fenofibrate formulations that can be taken with or without meals include nanoparticle tablets (Tricor $\left.{ }^{\circledR}\right)$, IDD-P tablets (Triglide $\left.{ }^{\circledR}\right)$, micronized capsules (Antara $\AA$ ), and the choline salt of fenofibric acid (Trilipix $\left.{ }^{\circledR}\right)$ in a dosage range of 40 to $200 \mathrm{mg}^{8}$

Literature reveals that Fenofibrate (FNO) shows poor flowability and compaction properties. To enhance the compressibility spherical crystallization, highly plastic granules. ${ }^{9}$ and melt sonication techniques has been reported. ${ }^{10}$

Cocrystallization of the drug powder to control the crystal packing and modulate tabletability which describes the capacity of a powder to be transformed into a tablet in a broader manufacturing perspective and compaction which enables bonding between particles are important improvement at the preformulation stage. The objectives of present investigation were to formulate cocrystals of fenofibrate with nicotinamide by solution cocrystallization technique, solid state characterization of cocrystals by FTIR, PXRD and Raman spectroscopy and to evaluate cocrystals for tableting performance.

\section{MATERIALS AND METHODS}

\section{Materials}

Fenofibrate was obtained as a gift sample from Alembic pharma, Pvt.Ltd. Vadodara. Nicotinamide were procured from Loba Chemie Pvt. Ltd. Mumbai. All other chemicals were of analytical grade.

\section{Preparation of Cocrystals by Solution crystallization technique}

Fenofibrate and nicotinamide were weighed in 1:1 molar ratio, dissolved in $20 \mathrm{ml}$ of ethanol with sonication. The saturated solution was kept overnight to evaporate solvent. The crystals were obtained after evaporation of ethanol; crystals were allowed to dry in the air. ${ }^{3}$

\section{Fourier Transform Infrared spectroscopy (FTIR)}

IR spectroscopy was conducted using a Shimadzu FTIRAffinity-1S Spectrophotometer (Shimadzu) and the spectrum was recorded in the wavelength region of $7800-350 \mathrm{~cm}^{-1}$. The procedure consisted of dispersing a sample (drug alone, or prepared cocrystals) in KBR.

\section{Powder X-Ray Diffraction Studies (P-XRD)}

The X-ray diffraction patterns of pure drug and the optimized crystals formulation were recorded using Bruker analytical X-ray diffraction (D2 Phase, Bruker) (Germany) with a copper target over the interval of 5-700 $2 \theta-1$. The conditions were voltage $20 \mathrm{kV}$, current $30 \mathrm{~mA}$, scanning speed $20 / \mathrm{min}$, temperature of acquisition: room temperature, detector: scintillation counter detector, sample holder: non-rotating holder. ${ }^{1}$

\section{Raman Spectroscopy}

The Raman spectra of the pure drug and prepared formulations were recorded in the spectral range of 0-5000 cm-1 using a Raman spectrometer (Bruker MultiRAM, Germany Make) equipped with an $\mathrm{Nd}$ : YAG laser source with an at excitation wavelength of $1064 \mathrm{~nm}$ and resolution $4 \mathrm{~cm}^{-1}$.

\section{Tableting Studies}

Approximately $250 \mathrm{mg}$ of powder was manually filled into a KBR press die and compressed at predetermined pressures (1 to 2.5 tons) to get flat-faced round tablets $(8 \mathrm{~mm})$ diameter, and thickness was measured by using digital venire caliper. The hardness was measured by using Monsanto Hardness Tester. The prepared formulations were also evaluated for Micromeritic properties

\section{RESULTS AND DISCUSSION}

\section{Fourier Transform Infrared spectroscopy (FTIR)}

The result of FTIR revealed considerable changes in the IR peaks of fenofibrate in prepared co-crystals when compared to pure drug thereby indicating the presence of hydrogen bonding in the co-crystals as shown in Table 1. Specific FNO peaks were observed at $2982 \mathrm{~cm}^{-1}$ indicates aromatic $\mathrm{C}-\mathrm{H}$ stretching, peak at $1587 \mathrm{~cm}-1$ indicates $\mathrm{C}=\mathrm{O}$ stretching whereas, peaks at $1241 \mathrm{~cm}^{-1}$ and $1087 \mathrm{~cm}^{-1}$ indicates aralkyl and dialkyl ether C-O stretching respectively. Also, peak at $757 \mathrm{~cm}-1$ indicates presence of halogen-hydrogen interaction. Specific nicotinamide peaks are also observed at $3151.69 \mathrm{~cm}^{-1}$, $1283 \mathrm{~cm}^{-1}$ and $1726.29 \mathrm{~cm}^{-1}$ indicating presence of aromatic $-\mathrm{NH} 2$ group, $\mathrm{CN}$ - stretching and $-\mathrm{C}=\mathrm{O}$ stretching respectively. In case of co-crystals prepared by $1: 1 \mathrm{~F}+\mathrm{N}$ and 1:2 F+N methods induces interaction which is 


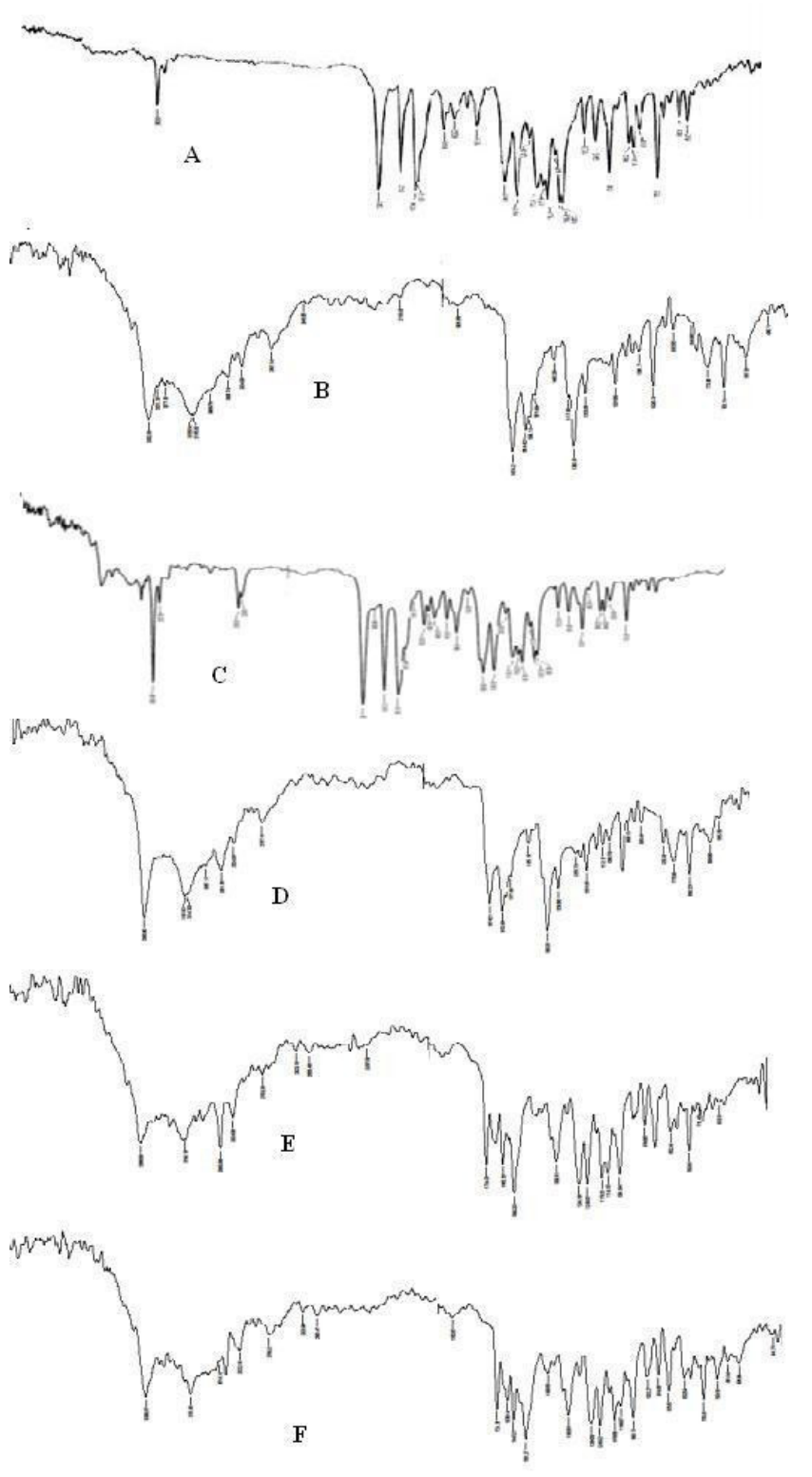

Figure 1: FTIR spectra's A.Pure fenofibrate B. Recrystallized Fenofibrate C. Pure Nicotinamide D. Recrystallized Nicotinamide E. 1:1 ratio cocrystals F. 1:2 ratio cocrystals.

indicated by appearance of characteristics peak of aromatic $-\mathrm{NH} 2$ group at $3151.69 \mathrm{~cm}^{-1}$ that might be involved in the interaction as shown in Figure 1. Those phenomena may be caused by the hydrogen bond interactions involved in co-crystal formation which changes the symmetry characteristic.

\section{Powder X-Ray Diffraction Studies (P-XRD)}

PXRD of all powders showed intense sharp diffraction peaks without amorphous halo observed. The PXRD pattern of fenofibrate as shown in Figure 2 indicates crystalline nature of drug. The sharp intense peaks at $2 \theta-11.88^{0}, 16.13^{0}, 20.75^{0}, 22.17^{0}, 24.55^{0}$ showed that the

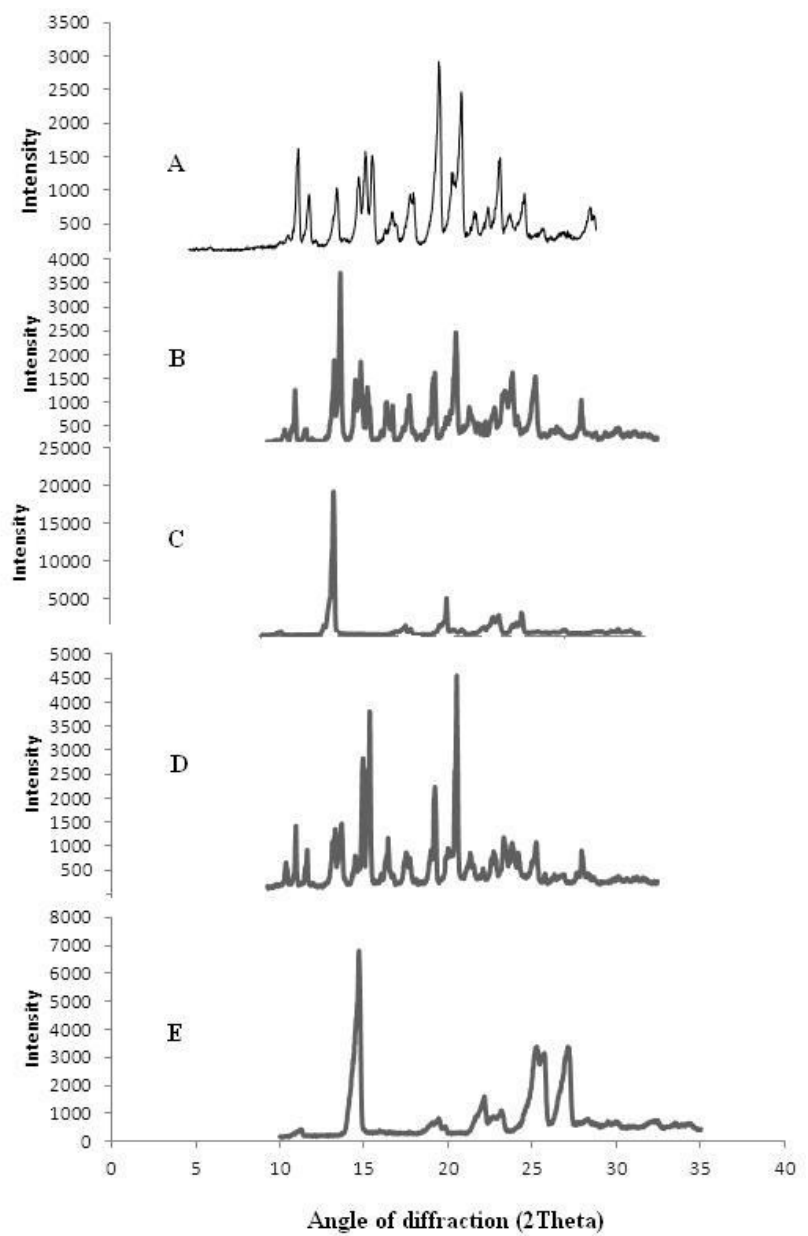

Figure 2: PXRD spectra's A.Pure fenofibrate B. Recrystallized Fenofibrate C. Pure Nicotinamide D. 1:1 ratio cocrystals E. 1:2 ratio cocrystals.

sample was fenofibrate. The pure nicotinamide showed intense peak at diffraction angle of $14.73^{\circ}$ and $22.20^{\circ}$. The PXRD pattern of 1:1 ratio cocrystals showed shifting in $2 \theta$ to $11.82^{\circ}, 14.73^{\circ}, 20.68^{\circ}, 22.12^{\circ}, 25.67^{\circ}$ and $1: 2$ ratio showed intense peak at $2 \theta-14.67^{\circ}, 22.04^{\circ}, 25.14^{\circ}$, $27.05^{\circ}$ as shown in Figure 2. This revealed a characteristic diffraction pattern, which differed from those of the two individual components. Hence shifting of the peaks has been observed in formulations. This shifting is a clear indication of formation of new phase's i.e. cocrystals. ${ }^{11,12}$ as confirmed from FTIR.

\section{Raman Spectroscopy}

The fenofibrate showed Raman bands at $1600 \mathrm{~cm}^{-1}$ and $1650 \mathrm{~cm}^{-1}$ for aromatic chain vibrations, $\mathrm{C}=\mathrm{O}$ functional group respectively. The $\mathrm{C}=\mathrm{C}$ bond is always strong and very reliable. "To form a salt with amine bases the carbonyl group bands shift to lower side by $30-40 \mathrm{~cm}^{-1}$ ". Such type of shifting has not been observed with formulations so it confirms the formed phases are 

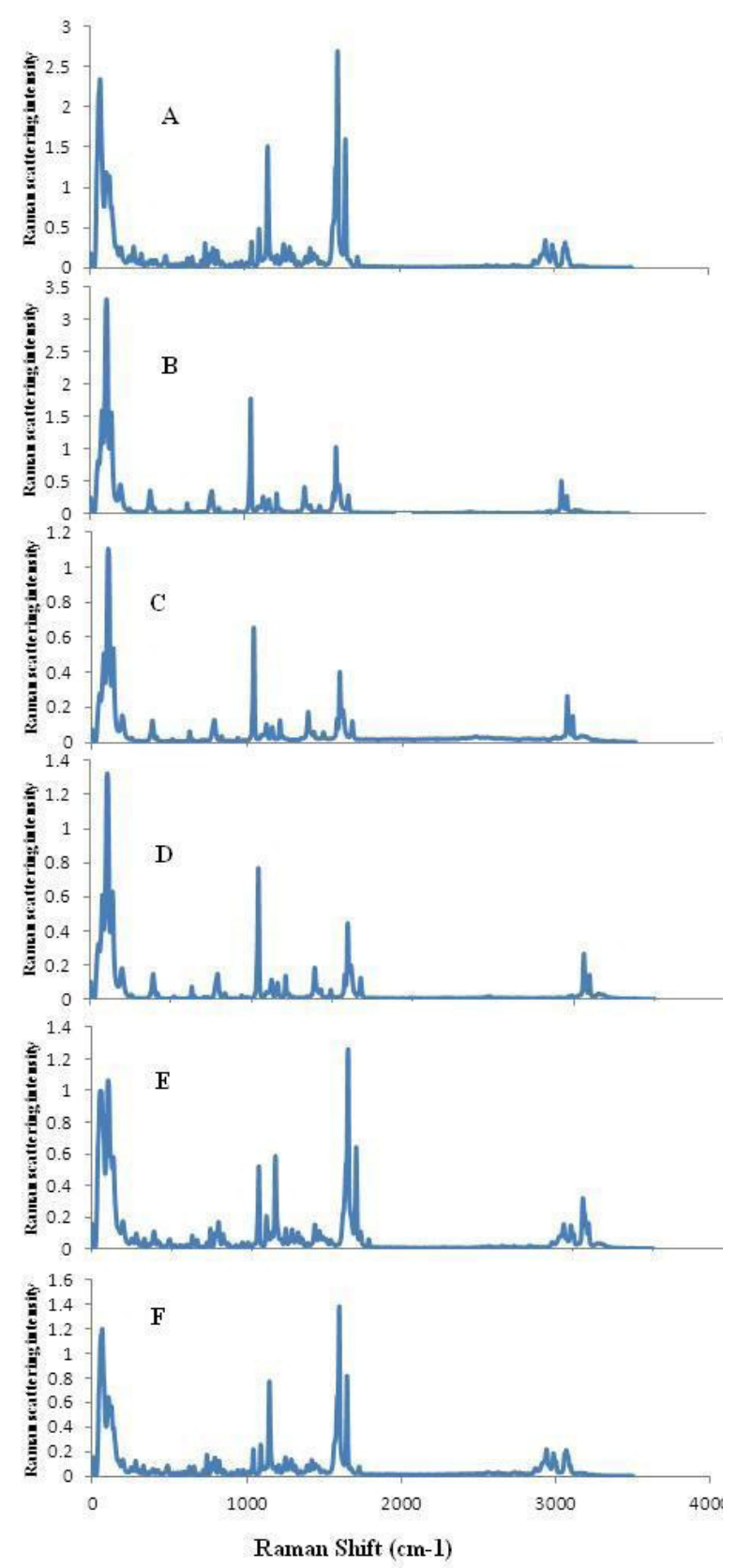

Figure 3: Raman Spectra's A.Pure Fenofibrate B. Recrystallized Fenofibrate C. Pure Nicotinamide D. 1:1 ratio cocrystals $E$. 1:2 ratio cocrystals.

cocrystals. The $\mathrm{C}-\mathrm{H}$ stretching region in between (3000$2850 \mathrm{~cm}-1)$ is a very good diagnostic bond for the presence of the aldehyde functional group. ${ }^{13,14,15}$ Similar to FTIR, some peak shift also take place for Raman spectra which can be attributed to intermolecular hydrogenbonding. The results are mentioned in Table 2 and Figure 3.

\section{Tableting Studies}

The Table 3 shows among all the formulations the 1:1 and 1:2 ratios of formulations showed better micromeritic

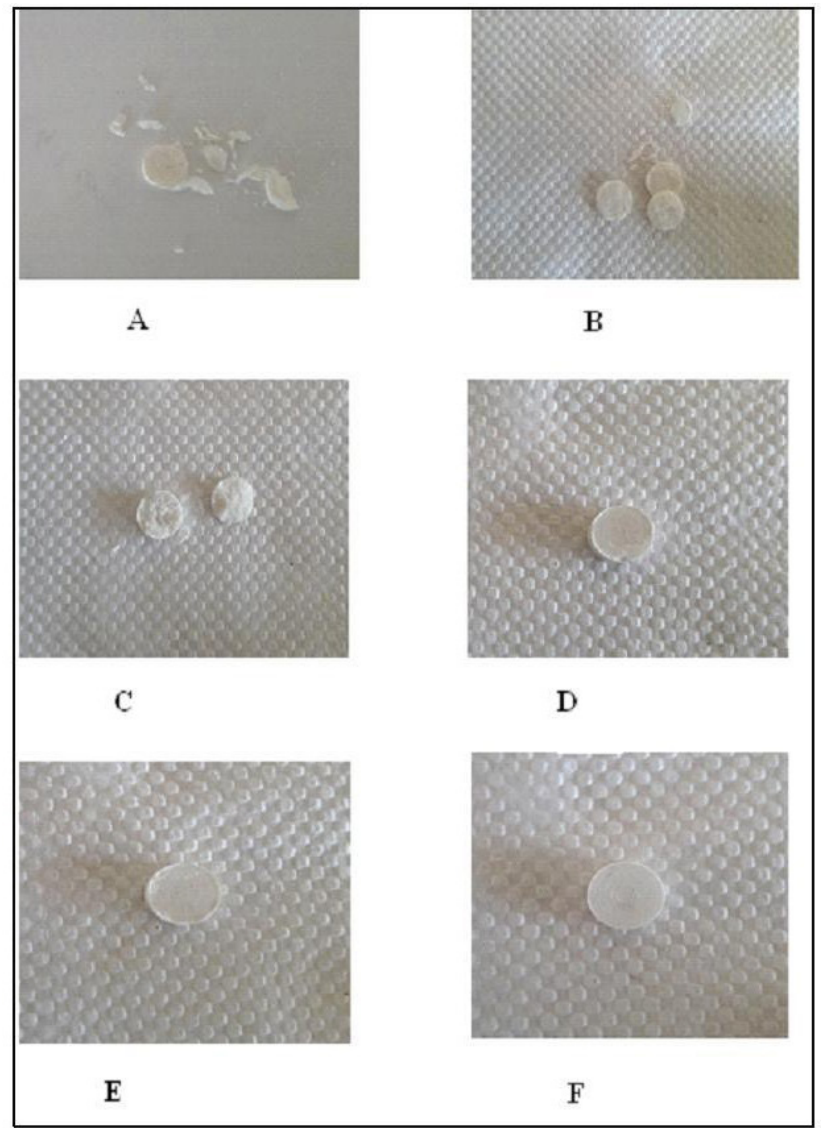

Figure 4: Photographs of tablets compressed at a pressure and weight ( 1.0 ton and $250 \mathrm{mg}$ ) respectively.

properties. The pure fenofibrate showed good angle of repose but moderate type of Hausner's ratio 1.399 and the having poor Carr's index $28.52 \%{ }^{16,17}$

The hardness and thickness of tablet at different applied pressure was determined. The 1:2 ratio based cocrystals are very useful in the formulation of stable tablet than pure drug. The 1:2 ratios of cocrystals of fenofibrate with nicotinamide showed better thickness and hardness properties among those formulations. The order of tableting performance 1:2 ratio cocrystals $>1: 1$ ratio cocrystals $>$ Recrystallized nicotinamide $>$ Nicotinamide $>>$ Recrystallized Fenofibrate $>>$ Fenofibrate as shown in Table 4 and 5. At any given compaction pressure, the tablet tensile strength of the co-crystal was always greater than that of pure fenofibrate and nicotinamdie. The different mechanical properties of Fenofibrate, Nicotinamide, and their 1: 1 co-crystal originate from differences in crystal packing. Fenofibrate crystals, which contain three dimensional hydrogen bonded networks, may exhibit low plasticity and high resistance to deformation. ${ }^{18}$ 


\begin{tabular}{|c|c|c|c|c|c|c|}
\hline \multicolumn{7}{|c|}{ Table 1: Summary of FTIR Peaks of Different Formulations } \\
\hline Formulation s & $\begin{array}{c}\text { C=0 } \\
\text { Str. }\end{array}$ & C=C & $\begin{array}{c}\text { C=0 } \\
\text { Aryl esters }\end{array}$ & H-X & CN & NH \\
\hline Fenofibrate (A) & 1587 & 1647.21 & 1726.29 & 757 & - \\
\hline Crystallized Fenofibrate (B) & 1587.06 & 1647.21 & 1724.36 & 763.81 & - & - \\
\hline Nicotinamide (C) & 1571.99 & 1683.86 & - & 763.81 & 1288.52 & - \\
\hline Crystallized Nicotinamide (D) & 1571.99 & 1674.21 & - & 776.30 & 1263.76 & 3067.17 \\
\hline Cocrystals (1:1 ratio) (E) & 1595.13 & 1645.34 & 1726.29 & 763.81 & 1283.52 & 3047 \\
\hline Cocrystals (1:2 ratio) (F) & 1597.66 & 1645.39 & 1726.29 & 763.81 & 1283 & 3151.69 \\
\hline
\end{tabular}

\begin{tabular}{|c|c|c|c|c|c|c|}
\hline Functional Group & $\begin{array}{l}\text { Lattice } \\
\text { vibrations }\end{array}$ & $\mathrm{u}(\mathrm{C}=\mathrm{S})$ & $\begin{array}{c}\mathrm{u}(\mathrm{CC}) \text { aromatic ring chain } \\
\text { vibrations }\end{array}$ & $\mathrm{u}(\mathrm{C}=\mathrm{C})$ & $\mathrm{u}(\mathrm{C}-\mathrm{H})$ & $\mathrm{u}(\mathrm{C}=\mathrm{H})$ \\
\hline Fenofibrate $(A)$ & 64.99 & 1146.9 & 1600 & 1650 & 2990.56 & - \\
\hline $\begin{array}{l}\text { Crystallized Fenofibrate } \\
\text { (B) }\end{array}$ & 107.41 & 1042.7 & 1598.16 & - & - & 3063.8 \\
\hline Nicotinamide (C) & 109.34 & 1042.7 & 1598.16 & - & - & 3063.8 \\
\hline $\begin{array}{l}\text { Crystallized Nicotinamide } \\
\text { (D) }\end{array}$ & 109.34 & 1042.7 & 1598.17 & - & - & 3063.8 \\
\hline Cocrystals (1:1 ratio) (E) & 111.27 & 1044.6 & - & 1650.23 & 2990.60 & 3065.7 \\
\hline Cocrystals (1:2 ratio) $(\mathrm{F})$ & 64.99 & 1146.89 & - & 1650.23 & 2986.70 & 3073.8 \\
\hline
\end{tabular}

\begin{tabular}{|c|c|c|c|c|c|}
\hline Formulation code & Angle of repose & $\begin{array}{l}\text { Bulk density }(\mathrm{gm} / \\
\left.\mathrm{cm}^{3}\right)\end{array}$ & $\begin{array}{l}\text { Tapped density } \\
\left(\mathrm{gm} / \mathrm{cm}^{3}\right)\end{array}$ & $\begin{array}{c}\text { Carr's } \\
\text { Index (\%) }\end{array}$ & Hausner's ratio \\
\hline Fenofibrate $(A)$ & $26.51 \pm 1.25$ & $0.238 \pm 0.012$ & $0.333 \pm 0.013$ & $28.52 \pm 1.20$ & $1.399 \pm 0.13$ \\
\hline $\begin{array}{l}\text { Crystallized Fenofibrate } \\
\text { (B) }\end{array}$ & $31.54 \pm 1.41$ & $0.274 \pm 0.021$ & $0.333 \pm 0.015$ & $17.71 \pm 1.32$ & $1.21 \pm 0.21$ \\
\hline Nicotinamide (C) & $26.51 \pm 1.75$ & $0.274 \pm 0.31$ & $0.320 \pm 0.028$ & $14.375 \pm 1.52$ & $1.167 \pm 0.24$ \\
\hline $\begin{array}{l}\text { Crystallized Nicotinamide } \\
\text { (D) }\end{array}$ & $25.032 \pm 1.20$ & $0.245 \pm 0.023$ & $0.316 \pm 0.023$ & $22.46 \pm 2.02$ & $1.28 \pm 0.26$ \\
\hline Cocrystals (1:1 ratio) (E) & $29.42 \pm 1.34$ & $0.304 \pm 0.024$ & $0.337 \pm 0.027$ & $9.55 \pm 1.52$ & $1.10 \pm 0.32$ \\
\hline Cocrystals (1:2 ratio) $(F)$ & $28.94 \pm 1.46$ & $0.297 \pm 0.028$ & $0.320 \pm 0.025$ & $7.0 \pm 1.23$ & $1.07 \pm 0.04$ \\
\hline
\end{tabular}




\section{Table 4: Thickness (Mm) of Tablet at Deferent Pressure}

\begin{tabular}{|c|c|c|c|c|c|c|}
\hline Compression Pressure in (tons) & A & B & C & D & $\mathbf{E}$ & $\mathbf{F}$ \\
\hline 1 & - & - & - & $3.65 \pm 0.04$ & $3.44 \pm 0.02$ & $3.60 \pm 0.02$ \\
\hline 1.5 & - & - & - & $3.40 \pm 0.04$ & $3.34 \pm 0.02$ & $3.45 \pm 0.02$ \\
\hline 2 & - & - & $3.13 \pm 0.04$ & $2.90 \pm 0.04$ & $2.95 \pm 0.02$ & $2.88 \pm 0.02$ \\
\hline 2.5 & - & - & $3.00 \pm 0.04$ & $2.88 \pm 0.04$ & $2.85 \pm 0.02$ & $2.82 \pm 0.02$ \\
\hline
\end{tabular}

\begin{tabular}{|c|c|c|c|c|c|c|}
\hline \multicolumn{2}{|c|}{ Table 5: Hardness $\left(\mathrm{Kg} / \mathbf{C m}^{2}\right)$ Of Tablet at Different Pressure (Mean Values) } \\
\hline Compression Pressure in (tons) & A & B & C & D & E & F \\
\hline 1 & - & - & - & 3.00 & 3.10 & 3.30 \\
\hline 1.5 & - & - & - & 3.10 & 3.30 & 3.50 \\
\hline 2 & - & - & 2.89 & 3.68 & 3.64 & 3.70 \\
\hline 2.5 & - & - & 2.99 & 3.69 & 3.74 & 3.79 \\
\hline
\end{tabular}

\section{CONCLUSION}

The cocrystals of antihyperlipedimic drug, fenofibrate with coformer nicotinamide have been successfully prepared. Cocrystals gives reliable thickness and hardness of the tablets. The cocrystal displayed superior tableting performance. This might be due to the co-crystals, containing hydrogen-bonded two dimensional flat slip planes exhibit higher plasticity.

\section{ACKNOWLEDGEMENT}

The authors are thankful to the management of Krishna Institute of Medical Sciences Deemed University's, Krishna Institute of Pharmacy Karad for providing excellent research facilities. Also grateful to Shivaji University, Kolhapur for providing the sophisticated analytical instrumentation facility (SAIF) of Shivaji University.

\section{CONFLICT OF INTEREST}

The authors report no conflicts of interest. The authors alone are responsible for the content and writing of the paper.

\section{ABBREVIATIONS USED}

FNO: Fenofibrate.

\section{REFERENCES}

1. Gadade DD, Pekamwar SS. Pharmaceutical Cocrystals: Regulatory and Strategic Aspects, Design and Development. Adv Pharm Bull. 2016; 6(4):479-94.

2. Bolla G, Nangia A. Pharmaceutical cocrystals: walking the talk. Chem Commun (Camb). 2016; 52(54):8342-60.

3. Guidance for industry regulatory classification of pharmaceutical co-crystals. U.S. Department of health and human services food and drug administration center for drug evaluation and research (CDER) April 2013.

4. Aitipamula S, Banerjee R, Bansal AK, Biradha K, Cheney M L, Choudhury A, et al,. Polymorphs, Salts, and Cocrystals: What's in a Name? Cryst Growth Des. 2012; 12(5):2147 -52. 
5. Harrison WTA, Yathirajan H S, Bindya S, Anilkumar HG, Devaraju. Escitalopram oxalate: co-existence of oxalate dianions and oxalic acid molecules in the same crystal. Acta Cryst. 2007; 63(2):0129-31.

6. Vogt M, Kunath K, Dressman JB. Dissolution enhancement of fenofibrate by micronization, cogrinding andspray-drying: comparison with commercial preparations. Eur J Pharm Biopharm. 2008; 68(2):283-8.

7. Shewale S, Shete AS, Doijad R C, Kadam SS, Patil V A, Yadav AV. Formulation and Solid State Characterization of Nicotinamide-based Co-crystals of Fenofibrate. Ind J Pharm Sci. 2015; 77(3):328.

8. Linga H, Luomab JT, Hilleman D. A Review of Currently Available Fenofibrate and Fenofibric Acid Formulations. Cardiol Res. 2013; 4(2):47-55.

9. Patent - CA 2524806 A1, Highly plastic granules for making fast melting tablets.

10. Patil SV, Patil SS, Kavathekar G. Influence of Process Parameters Compressibility, Solubility and Release Characteristics of Melt Sonocrystallized Fenofibrate. BJPR. 2016; 12(1):1-12.

11. Changquan CS, Hou H. Improving Mechanical Properties of Caffeine and Methyl Gallate Crystals by Cocrystallization. Crystal Growth and Design. 2008; 8(5):1575-9.
12. Grossjohanna C, Ecclesb KS, Maguirec AR, Lawrenceb SE, Tajbera L, Corrigana OI, et al,. Solubility and intrinsic dissolution behavior of benzamide: dibenzyl sulfoxide cocrystal. Int J Pharm. 2012; 422(4):24-32.

13. Mayo DW, Miller FA, Hannah RW. Course Notes on the Interpretation of Infrared and Raman Spectra: John Wiley and Sons, Inc, 2003, 0-471.

14. Paudel A, Raijada D, Rantanen J. Raman spectroscopy in pharmaceutical product design. Adv Drug Del Rev. 2015; 89:3-20.

15. Qiao N, Wang K, Schlindwein W, Davies A, Li M. In situ monitoring of carbamazepine-nicotinamide cocrystal intrinsic dissolution behavior. Eur $\mathrm{J}$ Pharm Biopharm. 2013; 83(3):415-26.

16. Martin A, Swarbrick J, Cammarata A, Chun AHC. (1991). Physical pharmacy, physical and chemical principles in the pharmaceutical sciences. Bombay: Varghese Publishing House.

17. Staniforth JN. Powder flow, the science of dosage forms designs. ELBS.1990; 610-13.

18. Chattoraj S, Shi L, Changquan CS. Understanding the relationship between crystal structure, plasticity and compaction behavior of theophylline, methyl gallate, and their 1: 1 co-crystal. CrystEngComm.2011; 11(8):2489-503.

\section{PICTORIAL ABSTRACT}

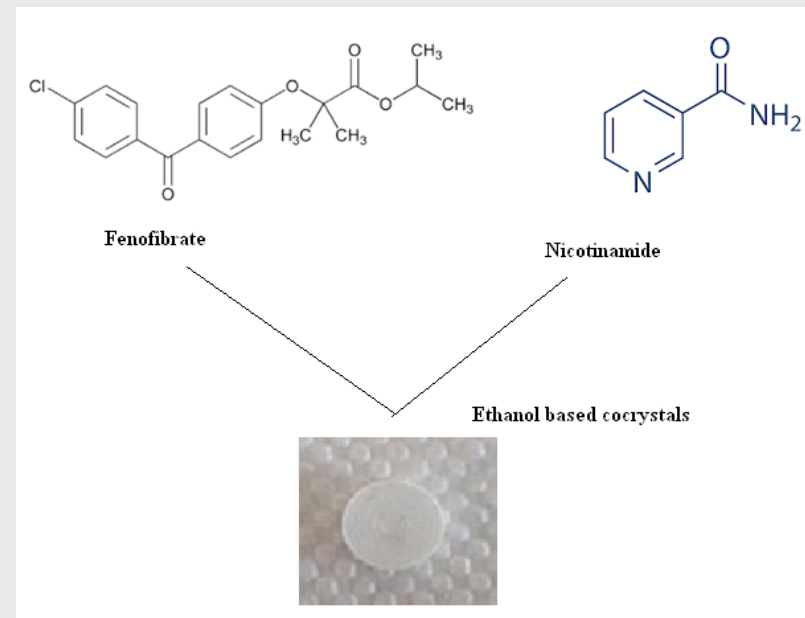

Improved tableting performance

\section{SUMMARY}

- Fenofibrate forms the cocrystals with Nicotinamide which has been confirmed by instrumental methods of analysis and the order of tableting performance $1: 2$ ratio cocrystals $>1: 1$ ratio cocrystals $>$ Recrystallized nicotinamide $>$ Nicotinamide $>>$ Recrystallized Fenofibrate $>>$ Fenofibrate. This might be due to the co-crystals, containing hydrogen-bonded two dimensional flat slip planes exhibit higher plasticity.

\section{About Authors}

Mr.Amol S.Shete: Presently he is working as an assistant professor department of pharmaceutics at Krishna Institute of Pharmacy of Krishna Institute of Medical Sciences Deemed University Karad. His area of interest is crystal engineering, evaluation of natural substances as pharmaceutical excipients, particulate drug delivery system.

Cite this article: Shete AS, Khandagale VV, Murthy SM, Yadav AV, Sakhare SS, Doijad RC. Solid State Characterization and Tableting Studies of Ethanol Based Cocrystals of Fenofibrate with Nicotinamide. Indian $\mathrm{J}$ of Pharmaceutical Education and Research. 2018;51(2):71-7. 